\title{
Conservação de grãos de pólen de mamoneira a baixas temperaturas
}

\author{
Cristina Copstein Cuchiara ${ }^{1 *}$, Sérgio Delmar dos Anjos e Silva ${ }^{2}$, Vera Lucia Bobrowski ${ }^{3}$
}

\section{RESUMO}

A finalidade do armazenamento do grão de pólen é conservar material para futura utilização, proporcionando-lhe condições ótimas, de forma a manter seu poder germinativo, vigor e integridade genética originais. O objetivo deste trabalho foi verificar o poder germinativo dos grãos de pólen de mamoneira (Ricinus communis L.), após armazenamento a baixas temperaturas. Para tanto, grãos de pólen dos cultivares IAC 80 e AL Guarany 2002 foram utilizados e armazenados em quatro temperaturas: -196, -72, -18 e $4{ }^{\circ} \mathrm{C}$, durante um período de oito semanas. A avaliação da viabilidade deste pólen foi realizada semanalmente, até completar cinco semanas, sendo realizada uma última avaliação após a oitava semana de armazenamento, por meio do teste de germinação in vitro. Meio de cultura, contendo $10 \mathrm{gL}^{-1} \mathrm{de}_{\text {gáar, }}$ $100 \mathrm{gL}^{-1}$ de sacarose, $0,004 \mathrm{gL}^{-1}$ de ácido bórico e pH 6,0, foi preparado e depositado em placas de lâmina escavada, onde o pólen foi distribuído sobre a superfície do meio. As placas foram incubadas a $20^{\circ} \mathrm{C}$ em BOD. O delineamento experimental foi inteiramente casualizado, em arranjo fatorial 2 x 4 ( 2 cultivares $\mathrm{x} 4$ temperaturas) para cada tempo de armazenamento, sendo analisados 100 grãos de pólen por repetição, totalizando seis de cada tratamento. Verificou-se diferença significativa entre os tratamentos para a interação cultivar x temperatura na quinta semana de observação ( $p$ $<0,05)$. Demais interações foram altamente significativas em todas as épocas de observação ( $\mathrm{p}<0,01)$. Portanto, a utilização de ultrabaixas temperaturas permite a manutenção da viabilidade de grãos de pólen de mamoneira, até a quinta semana de armazenamento.

Palavras-chave: armazenamento de pólen, viabilidade polínica, germinação in vitro, criopreservação.

\section{ABSTRACT}

\section{Conservation of castor bean pollen at low temperatures}

The objective of storing pollen is to preserve material for future use, providing optimal conditions to maintain their original germination, vigor and genetic integrity. The aim of this study was to investigate the germination of castor bean (Ricinus communis L.) pollen after storage at low temperatures. For this purpose, pollen of the cultivars IAC 80 and AL Guarany 2002 were used and stored at four different temperatures, $-196 ;-72 ;-18$; and $4^{\circ} \mathrm{C}$, for a period of 60 days. The pollen viability was assessed weekly for five weeks, with a last evaluation performed after eight weeks of storage using the in vitro germination test. Culture medium containing $10 \mathrm{gL}^{-1}$ agar, $100 \mathrm{gL}^{-1}$ sucrose, $0.004 \mathrm{~g} \mathrm{~L}^{-1}$ boric acid, pH 6.0 was prepared and poored into cavity slides, where the pollen was evenly distributed over the surface of the medium. The plates were incubated at $20^{\circ} \mathrm{C}$ in BOD. The experiment was arranged in a $2 \times 4$ factorial completely randomized design ( 2 cultivars $\mathrm{x} 4$ temperatures) for each storage time, with 100 pollen grains analyzed per repetition, totaling six of each treatment. There was significant difference between treatments for the cultivar $\mathrm{x}$ temperature interaction in the fifth week of observation $(\mathrm{p}<0.05)$. Other cultivar $\mathrm{x}$ temperature interactions were highly significant at all times of observation $(\mathrm{p}<0.01)$. It is therefore concluded that the use of ultra low temperatures allows the maintenance of castor bean pollen viability until the fifth week of storage.

Key words: pollen storage; pollen viability; in vitro germination; cryopreservation.

\footnotetext{
Recebido para publicação em 01/12/2010 e aprovado em 20/01/2012

${ }^{1}$ Bióloga, Mestre. Doutoranda do Programa de Pós-Graduação em Fisiologia Vegetal, Laboratório de Genética, Departamento de Zoologia e Genética, Instituto de Biologia, Universidade Federal de Pelotas. Campus Universitário s/n, Caixa Postal 354, 96010-900 Pelotas, Rio Grande do Sul, Brasil. cccuchiara@ hotmail.com (*Autora correspondente). ${ }^{2}$ Engenheiro-Agrônomo. Pesquisador Embrapa Clima Temperado. Caixa Postal 403, 96001-970, Pelotas, Rio Grande do Sul, Brasil. sergio@cpact.embrapa.br

${ }^{3}$ Engenheira-Agrônoma, Doutora. Laboratório de Genética, Departamento de Zoologia e Genética, Instituto de Biologia, Universidade Federal de Pelotas. Campus Universitário s/n, Caixa Postal 354, 96010-900 Pelotas, Rio Grande do Sul, Brasil. vera_bobrowski@hotmail.com
} 


\section{INTRODUÇÃO}

A mamoneira, conhecida cientificamente como Ricinus communis L., é uma xerófila caracterizada por ter tolerância à escassez de água e ser exigente em calor e luminosidade. Reconhecido como o petróleo verde, o óleo da mamona pode ser utilizado como fonte energética renovável, em substituição ao óleo diesel, e é considerado matéria-prima nacional, já que a mamoneira é uma planta adaptada aos solos brasileiro, podendo ser cultivada em qualquer parte do País (Chierice \& Claro Neto, 2001).

$\mathrm{O}$ armazenamento do grão de pólen para uso nos programas de melhoramento é requerido por várias situações, como a correção da não coincidência de florações, o intercâmbio com outros países ou outras regiões do país ou apenas para ser utilizado em cultivares de floração tardia. Neste caso, é recomendável testar sua viabilidade, antes, durante e após sua utilização (Einhardt et al., 2006). Segundo Dafni (1992), a avaliação da viabilidade dos grãos de pólen é o primeiro passo para se verificarem as chances que ele tem de germinar no estigma da flor, o que é crucial à fertilização.

A viabilidade polínica pode ser determinada por meio de um grande número de técnicas, sendo a mais utilizada a germinação in vitro (Soares et al., 2008), chamada de método direto (Dafni, 1992; Kearns \& Inouye, 1993). Esse método consiste em pôr a germinar uma pequena amostra, em meio apropriado, e observar em microscópio, depois de determinado período, o número de grãos de pólen que emitem tubo polínico (Galletta, 1983).

Segundo Souza et al. (2002), a viabilidade e a germinação do tubo polínico constituem fatores importantes para o melhoramento de plantas, pois cada grão de pólen leva consigo os materiais genéticos resultantes da recombinação. O cruzamento permite a transmissão às próximas gerações de genes altamente diversificados e promove a diversidade genética por diferentes combinações dos alelos durante a meiose.

O armazenamento do grão de pólen, com o objetivo de conservação genética, consiste em conservar material para futura utilização e, também, para proporcionar ao material condições ótimas, de forma que mantenha seu poder germinativo, vigor e integridade genética originais (Wang, 1975).

Para os melhoristas, a preservação da viabilidade do pólen soluciona dois dos maiores problemas da polinização manual, que são o tempo e o espaço, permitindo, assim, cruzamentos entre plantas situadas em diferentes localidades (Bissiri \& Niknejad, 1976). Tendo em vista a diversidade da utilização do material vegetal em estudo, o objetivo deste trabalho foi verificar o poder germinativo dos grãos de pólen de mamoneira (Ricinus communis L.) após armazenamento a baixas temperaturas.

\section{MATERIAL E MÉTODOS}

O trabalho foi conduzido no Laboratório de Genética da Universidade Federal de Pelotas - UFPel, Pelotas, no ano de 2009, durante o período de floração, março e abril, dos cultivares IAC 80 e AL Guarany 2002. Esses cultivares estavam localizados no campo experimental da Embrapa Clima Temperado - CPACT, no município de Pelotas, Rio Grande do Sul, na latitude $31^{\circ} 41^{\prime}$ S e longitude $52^{\circ} 21^{\prime} \mathrm{W}$ e altitude de $60 \mathrm{~m}$.

Para a realização do trabalho, foram selecionadas dez inflorescências de cada cultivar, coletadas aleatoriamente, em todas as partes da planta, no período da manhã, próximo às 8:00 $\mathrm{h}$. As inflorescências foram levadas e mantidas no laboratório, em água destilada, à temperatura ambiente, até a antese e retirada dos grãos de pólen, que, então, foram colocados em tubo tipo eppendorf e criotubos, para armazenamento.

Os tratamentos de conservação utilizados neste experimento consistiram em quatro temperaturas: -196, -72,-18 e 4 ${ }^{\circ} \mathrm{C}$, durante um período de oito semanas. A viabilidade dos grãos de pólen armazenados foi avaliada por meio do teste de germinação in vitro, com avaliações semanais, até completar cinco semanas e, depois, na oitava semana. Para essa avaliação, os grãos de pólen foram polvilhados sobre um meio de cultura, constituído de $10 \mathrm{gL}^{-1}$ de ágar, $100 \mathrm{gL}^{-1} \mathrm{de}$ sacarose e $0,004 \mathrm{gL}^{-1}$ de ácido bórico. $\mathrm{O} \mathrm{pH}$ do meio foi ajustado para 6,0 , o meio foi aquecido e, ainda quente, distribuído em lâmina escavada de Kline com 12 poros.

As lâminas foram colocadas em placas de Petri com fundo coberto por papel filtro umedecido (simulando câmara úmida) e levadas para incubação em câmara de germinação tipo BOD, com temperatura controlada a $20^{\circ} \mathrm{C}$.

Após 24 horas de incubação, realizou-se a contagem de grãos de pólen germinados, com microscópio óptico com aumento de 40x, num total de 100 polens/cavidade da placa. Cada cavidade foi considerada uma repetição, sendo utilizadas seis repetições por tratamento. Segundo Pasqual et al. (1982), foram considerados como germinados aqueles que apresentassem tubo polínico de comprimento igual ou superior ao diâmetro do próprio pólen, conforme Figura 1.

O delineamento experimental foi inteiramente casualizado, em arranjo fatorial $2 \times 4$ ( 2 cultivares $\times 4$ temperaturas) para cada tempo de armazenamento ( $1^{\mathrm{a}}$ semana, $2^{\mathrm{a}}$ semana, $3^{\text {a }}$ semana, $4^{\text {a }}$ semana, $5^{a}$ semana e $8^{a}$ semana). Os resultados obtidos foram submetidos à análise de variância e as médias foram comparadas pelo teste de Duncan $(\alpha=$ $1 \%$ ), com auxílio do programa estatístico SANEST (Zonta \& Machado, 1984). Os dados, expressos em percentagem, foram transformados segundo arco seno de $(\mathrm{X} / 100)^{1 / 2}$, em que $\mathrm{X}$ representa o valor percentual obtido para cada variável. As análises foram realizadas procurando-se verifi- 


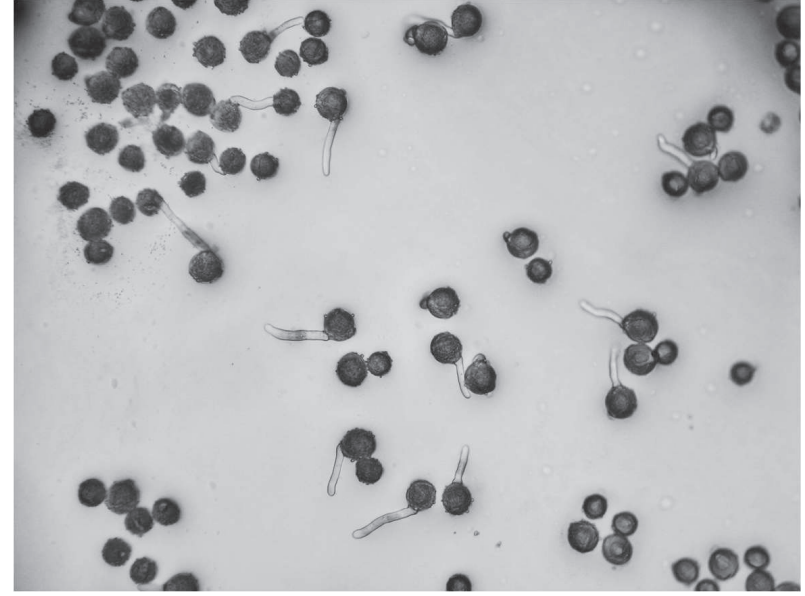

Figura 1. Emissão de tubo polínico em grãos de pólen de mamoneira (Ricinus communis L.), submetidos a teste de germinação in vitro. Aumento de 40x.

car o efeito das diferentes temperaturas de armazenamento dentro de cada cultivar estudado.

Neste trabalho, o controle experimental foi realizado por meio do teste de germinação in vitro de grãos de pólen antes do armazenamento, sendo chamado de pólen fresco (testemunha). De acordo com Pio et al. (2007), os resultados desse procedimento serviram de referência para a comparação da percentagem de grãos de pólen germinados após armazenamento. No entanto, não foi necessário avaliar o efeito do armazenamento dos grãos de pólen, à temperatura ambiente, por oito semanas, visto que, na abertura floral, o grão de pólen necessita estar viável e, com o passar do tempo, a viabilidade vai diminuindo e vai-se reduzindo sua eficiência na fertilização (Souza et al., 2002). Ou seja, à medida que o pólen envelhece, o comprimento do tubo polínico e a percentagem de germinação decrescem (Scorza \& Sherman, 1995; Einhardt et al., 2006). Sendo assim, somente a utilização de baixas temperaturas é capaz de manter a viabilidade polínica por longo período.

\section{RESULTADOS E DISCUSSÃO}

Tomando por base a análise de variação realizada, verificou-se diferença significativa entre os tratamentos, a $5 \%$ de probabilidade, para a interação cultivar $\mathrm{x}$ temperatura, na quinta semana de observação (Tabela 1). As demais interações foram altamente significativas, a $1 \%$ de probabilidade, em todas as épocas de observação, conforme se observa na Tabela 1. Esses resultados confirmam que a percentagem de germinação é dependente de diversos fatores, principalmente, aqueles relacionados com o armazenamento (Pio et al., 2007).

Os coeficientes de variação obtidos para os períodos avaliados foram baixos, levando a crer que os fatores externos tenham exercido pouca influência sobre as temperaturas de armazenamento (Tabela 1). Somente na oitava semana de armazenamento o coeficiente de variação foi relativamente alto, por causa da germinação dos grãos de pólen do cv. AL Guarany 2002, conservados em $-72{ }^{\circ} \mathrm{C}$, enquanto os outros tratamentos a frio causaram a inviabilidade dos grãos de pólen dos dois cultivares testados na mesma época.

Conforme resultados mostrados na Tabela 2, o armazenamento do pólen de ambos os cultivares, a $4{ }^{\circ} \mathrm{C}$, não foi eficiente, pois foi observada redução drástica na viabilidade polínica, ao longo do armazenamento, quando comparado com a percentagem de germinação de pólen fresco. Estes resultados discordam dos apresentados por Gomez et al. (2000) e Siregar \& Sweet (2000), que mantiveram grãos de pólen de amendoeira (Prunus dulcis) e de Pinus spp., respectivamente, armazenados a $4^{\circ} \mathrm{C}$, por vários meses. Embora tendo apresentado um decréscimo de viabilidade em função do tempo de armazenamento, esse decréscimo não foi tão drástico.

No entanto, os grãos de pólen do cv. IAC 80 mantiveram um percentual de germinação maior que o dos grãos de pólen do cv. AL Guarany 2002, durante todo o período do experimento, demonstrando serem menos sensíveis aos danos causados pelo armazenamento a $4{ }^{\circ} \mathrm{C}$ (Tabela 2 ).

Os grãos de pólen mantidos a $-18{ }^{\circ} \mathrm{C}$ apresentaram maior percentagem de germinação do que aqueles armazenados $4{ }^{\circ} \mathrm{C}$, durante a execução do experimento, tendose encontrado, na quinta semana de conservação, 7,93\% de viabilidade para o cv. IAC 80 e $12,62 \%$ para o cv. AL Guarany 2002 (Tabela 2).

Em geral, no que diz respeito à viabilidade do grão de pólen em cada tempo de armazenamento, nota-se que o pólen armazenado a $4{ }^{\circ} \mathrm{C}$ perdeu sua viabilidade muito rapidamente, em relação ao armazenado a $-18^{\circ} \mathrm{C}$, no mesmo período de tempo. Mesmo assim, foi possível verificar que houve redução menos drástica da viabilidade com o tempo de conservação. Já, na oitava semana de armazenamento, houve inviabilidade total dos grãos de pólen armazenados tanto a $4{ }^{\circ} \mathrm{C}$ quanto a $-18^{\circ} \mathrm{C}$ (Tabela 2). Resultados semelhantes foram encontrados em trabalho com conservação de pólen de mamoeiro (Carica papaya L.) conforme Damasceno Júnior et al. (2008), em que os ambientes a $4{ }^{\circ} \mathrm{C}$ e a $-18^{\circ} \mathrm{C}$ não influenciaram para diferenças significativas para os grãos de pólen armazenados no botão floral. No entanto, com o passar do tempo foi observada redução significativa da viabilidade dos grãos de pólen armazenados a essas temperaturas.

A viabilidade dos grãos de pólen estocados a -72 ${ }^{\circ} \mathrm{C}$ decresceu lentamente com o passar do tempo. Para o cv. IAC 80, o percentual de tubos polínicos germinados permaneceu alto até a quarta semana, decaindo logo após a quinta semana. Já para o cv. AL Guarany 2002 também houve um decréscimo gradativo com o passar do tempo; porém, na oitava semana de armazenamento, foi observa- 
do que 9,23\% dos grãos de pólen germinaram. Ainda que a percentagem de grãos de pólen viáveis seja baixa, a presença de alguns tubos polínicos vigorosos indica que o grão de pólen é suficientemente bom para assegurar, pelo menos, uma moderada frutificação efetiva, apesar da baixa percentagem de germinação (Einhardt et al., 2006). O mesmo pôde ser observado por Vargas et al. (2009), que relataram que, entre as temperaturas de -196, -72, -18 e 4 ${ }^{\circ} \mathrm{C}$, testadas durante 15 e 30 dias, o melhor índice de germinação de pólen ocorreu quando foi utilizada a temperatura de $-72{ }^{\circ} \mathrm{C}$ para armazenamento, podendo, desta forma, ser considerado o mais eficiente entre os sistemas testados pelo autor.

Esta maior eficiência na conservação a ultrabaixas temperaturas pode estar relacionada com a maior velocidade de congelamento, que causa menores danos à célula, por menor desidratação e menos rompimento de membranas (Dumont et al., 2004; Fellows, 2006).

Segundo Almeida et al. (2002), a técnica da crioconservação, isto é, o armazenamento a $-196{ }^{\circ} \mathrm{C}$, proporciona potencial para uma preservação sem limites de tempo, com a redução do metabolismo a níveis tão baixos que todos os processos bioquímicos são significativamente reduzidos e a deterioração biológica é virtualmente paralisada. Para os cultivares de mamoneira estudados neste trabalho, a técnica de criopreservação foi muito eficiente até a quinta semana de armazenamento, permitindo a manutenção do poder germinativo durante esse período, principalmente, para o cv. AL Guarany 2002.

Tabela 1. Resumo das análises de variância da percentagem de germinação de grãos de pólen de mamoneira (Ricinus communis L.), submetidos a armazenamento em baixas temperaturas, avaliados em diferentes épocas

\begin{tabular}{|c|c|c|c|c|c|}
\hline \multirow{2}{*}{ Causas da Variação } & \multirow{2}{*}{ GL } & \multicolumn{4}{|c|}{ Quadrado Médio } \\
\hline & & Pólen Fresco & GL & $1^{\mathrm{a}}$ semana & $2^{\mathrm{a}}$ semana \\
\hline Cultivar & 1 & $116,5^{*}$ & 1 & $1259,7 * *$ & $16,5 \mathrm{~ns}$ \\
\hline Temperatura & - & - & 3 & $499,2 * *$ & $140,5^{* *}$ \\
\hline Cultivar X Temperatura & - & - & 3 & $97,6^{* *}$ & $285,3 * *$ \\
\hline Resíduo & 10 & 12,9 & 40 & 19,4 & 10,9 \\
\hline C.V. $(\%)$ & & 8,84 & & 11,92 & 11,89 \\
\hline Média Geral (\%) & & 40,73 & & 36,94 & 27,81 \\
\hline \multirow{2}{*}{ Causas da Variação } & \multirow{2}{*}{ GL } & \multicolumn{4}{|c|}{ Quadrado Médio } \\
\hline & & $3^{\mathrm{a}}$ semana & $4^{a}$ semana & $5^{\mathrm{a}}$ semana & $8^{\text {a }}$ semana \\
\hline Cultivar & 1 & $22,3 \mathrm{~ns}$ & $45,1 \mathrm{~ns}$ & $165,9 * *$ & $346,7 * *$ \\
\hline Temperatura & 3 & $575,0 * *$ & $627,1 * *$ & $1811,5^{* *}$ & $194,8 * *$ \\
\hline Cultivar X Temperatura & 3 & $164,2 * *$ & $395,4 * *$ & $37,0 *$ & $198,7 * *$ \\
\hline Resíduo & 40 & 11,8 & 16,6 & 9,6 & 11,5 \\
\hline C.V. $(\%)$ & & 11,93 & 14,65 & 14,00 & 90,50 \\
\hline Média Geral (\%) & & 28,85 & 27,87 & 22,17 & 3,75 \\
\hline
\end{tabular}

Tabela 2. Percentagem de germinação de grãos de pólen de mamoneira (Ricinus communis L.) cultivares IAC 80 e AL Guarany 2002, submetidos a tratamentos de baixas temperaturas de armazenamento

\begin{tabular}{|c|c|c|c|c|c|c|c|}
\hline \multicolumn{8}{|c|}{ IAC 80} \\
\hline Tratamento & Pólen Fresco & $1^{\mathrm{a}}$ semana & $2^{\mathrm{a}}$ semana & $3^{a}$ semana & $4^{a}$ semana & $5^{\mathrm{a}}$ semana & $8^{\text {a }}$ semana \\
\hline $4^{\circ} \mathrm{C}$ & 47,99 & $31,99 \mathrm{~b}$ & $25,48 \mathrm{a}$ & $15,36 \mathrm{~b}$ & $13,72 \mathrm{~b}$ & 0,94 & $0,00 \mathrm{a}$ \\
\hline$-18^{\circ} \mathrm{C}$ & 47,99 & 54,40 a & $23,84 \mathrm{a}$ & $24,92 \mathrm{a}$ & $14,99 \mathrm{~b}$ & $7,93 \quad b$ & $0,17 \mathrm{a}$ \\
\hline$-72^{\circ} \mathrm{C}$ & 47,99 & $44,81 \mathrm{a}$ & $25,57 \mathrm{a}$ & $30,94 \mathrm{a}$ & $41,62 \mathrm{a}$ & $24,77 \mathrm{a}$ & $0,02 \mathrm{a}$ \\
\hline$-196^{\circ} \mathrm{C}$ & 47,99 & $53,01 \mathrm{a}$ & $10,58 \mathrm{~b}$ & $27,02 \mathrm{a}$ & $15,17 \mathrm{~b}$ & $24,21 \mathrm{a}$ & $0,02 \mathrm{a}$ \\
\hline \multicolumn{8}{|c|}{ AL Guarany 2002} \\
\hline Tratamento & Pólen Fresco & $1^{a}$ semana & $2^{\mathrm{a}}$ semana & $3^{\text {a }}$ semana & $4^{a}$ semana & $5^{\mathrm{a}}$ semana & $8^{\text {a }}$ semana \\
\hline $4{ }^{\circ} \mathrm{C}$ & 37,25 & 20,6 bc & $10,58 \mathrm{~b}$ & $8,22 \quad \mathrm{c}$ & $11,39 \mathrm{c}$ & $1,62 \mathrm{~d}$ & $0,00 \mathrm{c}$ \\
\hline$-18^{\circ} \mathrm{C}$ & 37,25 & $30,35 \mathrm{~b}$ & $29,64 \mathrm{a}$ & $18,29 \mathrm{~b}$ & $15,26 \mathrm{c}$ & $12,62 \mathrm{c}$ & $0,05 \mathrm{c}$ \\
\hline$-72^{\circ} \mathrm{C}$ & 37,25 & $19,03 \mathrm{c}$ & 25,70 a & $24,62 \mathrm{~b}$ & $27,35 \mathrm{~b}$ & $25,29 \mathrm{~b}$ & $9,23 \mathrm{a}$ \\
\hline$-196^{\circ} \mathrm{C}$ & 37,25 & $43,04 \mathrm{a}$ & 26,78 a & 42,96 a & $43,28 \mathrm{a}$ & 37,56 a & $1,37 \mathrm{~b}$ \\
\hline
\end{tabular}

* Médias, seguidas de letras minúsculas, diferem estatisticamente a $1 \%$ de probabilidade de erro pelo teste de Duncan, nas colunas. 
Resultados contraditórios foram apresentados em trabalhos com Annona spp., em que a utilização de $-196{ }^{\circ} \mathrm{C}$ não foi eficiente, pois os efeitos de seu uso, quando comparados com os de $4{ }^{\circ} \mathrm{C}$, não causaram aumento da longevidade do pólen das espécies de Annona estudadas (Bettiol Neto et al., 2009).

No entanto, nenhum dos ambientes de conservação estudados proporcionou mais de oito semanas de conservação com total viabilidade do grão de pólen, evidenciando-se que os grãos de pólen de mamoneira são muito sensíveis a mudanças de temperaturas.

Nos grãos de pólen, o efeito de baixas temperaturas está relacionado com a redução do metabolismo celular, propiciando-lhes maior longevidade. Uma das maiores dificuldades do processo de armazenamento de grãos de pólen é a formação de cristais de gelo no interior das células, os quais podem causar ruptura das membranas, resultando em colapso e morte, como consequência da perda da semipermeabilidade e da compartimentação celular (Santos et al., 2002; Salomom, 2003). A injúria mecânica sofrida pelas células advém de dois fenômenos: o comportamento peculiar da água, que se expande ao congelar-se, e a formação dos cristais de gelo (Santos, 2001).

Outra explicação seria que as alterações fisiológicas ocasionalmente ocorridas durante o armazenamento do grão de pólen podem levar ao decréscimo da viabilidade. Alteração na velocidade de respiração e de conversão de açúcares em ácidos orgânicos, acúmulo de produtos metabólicos secundários e alteração dos lipídeos da exina do pólen são exemplos de tais transformações (Stanley \& Linskens, 1974).

As diferenças observadas quanto à germinabilidade do pólen, dentro da mesma temperatura, mas em tempos diferentes, podem ter ocorrido por vários fatores, como as condições de armazenamento, o recipiente usado no acondicionamento do pólen e a manipulação dos recipientes (Oliveira et al., 2001). O estado nutricional da planta fornecedora de pólen é, também, um fator a ser considerado. Stanley \& Linskens (1974) evidenciaram que o estado nutricional da planta durante o desenvolvimento do pólen pode afetar sua longevidade.

De acordo com Baéz et al. (2002), Gibernau et al. (2003) e Khan \& Perveen (2006), em grãos de pólen armazenados a baixas temperaturas não se observa aumento de viabilidade polínica com o passar do período de armazenamento, mas, sim, decréscimo. Portanto, os resultados mencionados estão de acordo com os encontrados na literatura, ou seja, com o passar do tempo observou-se redução significativa da viabilidade dos grãos de pólen armazenados e a decisão com respeito ao método a ser empregado no armazenamento dependerá do objetivo e do tempo exigido para seu alcance, ou seja, a longo ou a médio prazo (Pio, 2003).

\section{CONCLUSÃO}

A utilização de ultrabaixas temperaturas permite a manutenção da viabilidade de grãos de pólen de mamoneira cvs. IAC 80 e AL Guarany 2002 até a quinta semana de conservação.

\section{REFERÊNCIAS}

Almeida FAC, Morais AM, Carvalho JMFC \& Gouveia JPG (2002) Crioconservação de sementes de mamona das variedades nordestina e pernambucana. Revista Brasileira de Engenharia Agrícola e Ambiental, 6:295-302.

Baéz P, Riveros M \& Lehnebach C (2002) Viability and longevity of pollen of Nothofagus species in south Chile. Journal of Botany, 40:671- 678.

Bettiol Neto JE, Del Nero M, Kavati R \& Pinto-Maglio CAF (2009) Viabilidade e conservação de pólen de três anonas comerciais. Bragantia, 68:825-837.

Bissiri MK \& Niknejad M (1976) Effects temperature and humidity on pollen viability of six rose species. Canadian Journal of Plant Science, 56:517-523.

Chierice GO \& Claro Neto S (2001) Aplicação industrial do óleo. In: Azevedo DMP de \& Lima EF (Org.) O agronegócio da mamona no Brasil. Brasília, Embrapa Comunicação para Transferência de Tecnologias. p.89-120.

Dafni A (1992) Pollination ecology: a practical approach. New York, Oxford University Press. 250p.

Damasceno Junior PC, Pereira TNS, Pereira MG \& Silva FF (2008) Conservação de grão de pólen de mamoeiro. Revista Ceres, $55: 433-438$

Dumont F, Marechal PA \& Gervais P (2004) Cell size and water permeability as determining factors for cell viability after freezing at different cooling rates. Applied and Environmental Microbiology, 70:268-272.

Einhardt PM, Correa ER \& Raseira MCB (2006) Comparação entre métodos para testar a viabilidade de pólen de pessegueiro. Revista Brasileira de Fruticultura, 28:5-7.

Fellows PJ (2006) Tecnologia do processamento de alimentos: princípios e práticas. Porto Alegre, Artmed. 602p.

Galletta GJ (1983) Pollen and seed management. In: Moore JN \& Janick J (Eds.) Methods in fruit breeding. Indiana, Purdue University Press. p.23-47.

Gibernau M, Marquart D \& Diaz A (2003) Pollen viability and longevity in two especies of Arum. Aroideana, 26:58-62.

Gomez P, Gradziel TM, Ortega E \& Dicenta F (2000) Short term storage of almond pollen. HortScience, 35:151-152.

Kearns CA \& Inouye DW (1993) Techniques for pollination biologists. Niwot, University Press of Colorado. 583p.

Khan SA \& Perveen A (2006) Germination capactity of stored pollen of Abelmoschus esculentus L. (Malvaceae) and their maintenance. Pakistan Journal of Botany, 38:233-236.

Oliveira MSP, Maués MM \& Kalume MAA (2001) Viabilidade de pólen in vivo e in vitro em genótipos de açaizeiro. Acta Botânica Brasílica, 15:63-67.

Pasqual M, Petri JL \& Mattos CS (1982) Polinização da macieira III: cultivares BR-1 e Mollies Delicious. Pesquisa Agropecuária Brasileira, 17:1477-1481

Pio LAS (2003) Viabilidade do pólen de citros em diferentes condições de armazenamento. Dissertação de Mestrado. Universidade Federal de Lavras, Minas Gerais, 45p. 
Pio LAS, Ramos JD, Pasqual M, Junqueira KP, Santos FC \& Rufini JCM (2007) Viabilidade do pólen de laranjas doces em diferentes condições de armazenamento. Ciência e Agrotecnologia, $31: 147-153$.

Salomom MV (2003) Trigo: avaliação de linhagens diplóides obtidas via cultura de anteras. Dissertação de Mestrado. Escola Superior de Agricultura "Luiz de Queiroz", Piracicaba, 180p.

Santos IRI (2001) Criopreservação de germoplasma vegetal. Biotecnologia, Ciência \& Desenvolvimento, 20:60.

Santos IRI, Salomão AM, Mundim RC \& Ribeiro FNS (2002) Criopreservação de eixos embrionários zigóticos de café (Coffea arabica L.). Brasília, Embrapa-Cenargen. 4p. (Comunicado Técnico, 69).

Scorza R \& Sherman WB (1995) Peaches. In: Janik J \& Moore JN (Eds.) Fruit breeding. New York, John \& Sons. p.325-440.

Siregar IZ \& Sweet GB (2000) The impact of extraction and storage conditions on the viability of radiata pine pollen. Silvae Genetica, 49:10-14.
Soares TL, Silva SO, Costa MAPC, Santos-Serejo JA, Souza AS, Lino LSM, Souza EH \& Jesus ON (2008) In vitro germination and viability of pollen grains of banana diploids. Crop Breending and Applied Biotechnology, 8:111-118.

Souza MM, Pereira TNS \& Martins ER (2002) Microsporogênese e microgametogênese associadas ao tamanho do botão floral e da antera e viabilidade polínica em maracujazeiro-amarelo (Passiflora edulis f. flavicarpa O. Deg.). Ciência e Agrotecnologia, 26:1209-1217.

Stanley RG \& Linskens HF (1974) Pollen - biology, biochemistry and management. New York, Springer-Verlag. 172p.

Vargas DP, Souza SAM, Silva DAS \& Bobrowski VL (2009) Análise dos grãos de pólen de diferentes cultivares de mamona (Ricinus communis L., Euphorbiaceae): conservação e viabilidade. Arquivo do Instituto Biológico, 76:115-120.

Zonta EP \& Machado AA (1984) SANEST - Sistema de análise estatística para microcomputadores. Pelotas, UFPel. 138p.

Wang BSP (1975) Metodología de la conservación de los recursos genéticos forestales. Roma, FAO. p.93-103. 